\title{
Prayer and marital intervention: Asking for divine help... or professional trouble?
}

Loren D. Marks

Brigham Young University - Provo, loren_marks@byu.edu

Follow this and additional works at: https://scholarsarchive.byu.edu/facpub

Part of the Other Social and Behavioral Sciences Commons

\section{Original Publication Citation}

Marks, L. D. (2008). Prayer and marital intervention: Asking for divine help... or professional trouble? Journal of Social and Clinical Psychology, 27, 678-685.

\section{BYU ScholarsArchive Citation}

Marks, Loren D., "Prayer and marital intervention: Asking for divine help... or professional trouble?" (2008). Faculty Publications. 4902.

https://scholarsarchive.byu.edu/facpub/4902 


\section{PRAYER AND MARITAL INTERVENTION: ASKING FOR DIVINE HELP ... OR PROFESSIONAL TROUBLE?}

LOREN D. MARKS

Louisiana State University

My selected title for this response piece reflects the late David Larson's identification of religion as the university's "anti-tenure topic." Beach, Fincham, Hurt, MCNair, and Stanley (hereafter, the authors) have stepped upon some dangerous soil. However, this statement is intended as a welcome, not a threat. I appreciate the authors' efforts to break new ground in an important but highly sensitive domain.

\section{WHY SHOULD SOCIAL, CLINICAL, AND COUNSELING PSYCHOLOGISTS CARE ABOUT PRAYER?}

Only 33\% of psychologists report that religious faith is important in their own lives (Plante, 1999), and social scientists are among the least religious participants in the academy (Stark \& Finke, 2000). This is our dominant professional and social context, one that we may inadvertently generalize to broader society. By contrast, $95 \%$ of all married couples and parents in the U.S. report a religious affiliation (Mahoney, Pargament, Tarakeshwar, \& Swank, 2001), and 60\% say religion is "important" or "very important" to them (McCullough et al., 2000). By extension, religious issues like prayer arise in marital intervention. This is especially true in certain geographical regions (e.g., the South and the Midwest) and with certain populations, including, but not limited to, the African-American population that stimulated the article we are considering. For many of the partici-

Correspondence concerning this article should be addressed to Loren Marks, associate professor in the School of Human Ecology at Louisiana State University, Baton Rouge, LA 70803. E-mail: lorenm@1su.edu. 
pants/clients from the $60 \%$ who view religion as "important" or "very important," a failure to ever mention faith and/or prayer at may be viewed not only as an omission but as a rejection-one severe enough to prompt discontinuance. This issue should be noted by all practitioners, regardless of our personal stance on faith.

\section{WHAT THE AUTHORS SAID AND WHAT THEY DID NOT SAY}

First, the authors are not promoting proselytizing. This piece is an effort to respond to an issue that is both pervasive and pre-existent in the authors' clinical sample. The authors state, "A wise therapist will generally inquire first of the couple about their beliefs and practices, and then, in that context, explore with the couple" their desire for prayer. They continue, " $[\mathrm{M}]$ arital and family therapists ignore the influence of prayer at their peril." While this may seem an overstatement to some psychologists, we must remember that our largely non-religious (and not infrequently, anti-religious) professional context is discordant with $60 \%$ of Americans. This discord seems to be underscored by the authors' reminder that "pastoral counselors see more couples than do all other kinds of [secular] helping professionals combined." On one hand, it is encouraging to note that there is a context where troubled American couples feel comfortable seeking intervention. However, it is discouraging to note that many of these couples are wrestling with issues that require more specialized intervention than most pastoral counselors can provide. I say this, not in hostile critique, but as one acquainted with many pastoral counselors who find themselves in "over their heads" but who have difficulty finding secular clinicians who are respectful of (and responsive to) their congregant-clients' central beliefs and practices. As a result, referrals are not made and the couple loses, thereby begging the question, "How can a secular marital intervention program be more friendly to the majority of Americans who are inclined towards faith and prayer?"

\section{THREE WAYS TO INTEGRATE PRAYER}

The authors posit that prayer can be integrated into marital intervention in three ways: First, as an alternative method of marital intervention; second, as an addition to marital intervention; and third, as a 
transformative strategy. I will discuss some thoughts and questions that each of these integrations prompted.

Prayer as an Alternative Approach to Marital Intervention. First, the authors mention prayer as an alternative approach to promoting desirable clinical processes and objectives (including regaining perspective, breaking negative thought cycles, and promoting the relaxation response). A corresponding point is overlooked, however. Prayer may promote key desirable outcomes, but it may also soften or eliminate negative processes. For example, a frustrated husband who turns to prayer may or may not "regain perspective," "break negative thought cycles," or "relax" as the authors posit, but at least he has not turned to alcohol, drugs, or violence. This is no minor point given that $80 \%$ of domestic violence is alcohol-related (Kroll \& Taylor, 2003). In short, we should also consider prayer in terms of coping and prevention, not just intervention.

Prayer as an addition to marital intervention. In this section the authors again discuss key desirable processes and objectives that may be facilitated by prayer (including highlighting the view of an important "other", highlighting peer attitudes, producing a shift in associative networks, and tapping new sources of motivation). Upon reflection, these addition-related processes and objectives seem to differ qualitatively from those noted in the "prayer as an alternative" section. Specifically, the alternative-related processes (i.e., gaining perspective, thinking, relaxing) are individual, while the additive-related processes (i.e., focusing on the "other," being sensitive to peers, network shifting, etc.) are primarily interpersonal. This distinction may be profitably considered and highlighted in the authors' subsequent work.

On this note of interpersonal processes, the authors touch on a vital point when they mention that prayer is often "socially sanctioned and appropriate" and that for those who are active in a faith, prayer may be "imbedded in their community context" and feel more natural than other actions. A related consideration for the authors' future work might be that prayer is not only a socially sanctioned appeal for personal and marital help from God; prayer also provides a socially sanctioned way to summon marital help and support from fellow members of one's faith community (i.e., the request "please pray for us" often serves as a euphemistic signal to others that a marriage or family is facing challenges). 
Prayer as a Transformative Strategy. The authors' discussion of prayer as a transformative strategy is rooted heavily in their previous work (Fincham, Stanley, \& Beach, 2007). By the authors' report, "Transformative processes have received relatively little empirical attention in marital research and therapy, making claims about marital transformation difficult to evaluate." Further, there are virtually no data that specifically address prayer as a catalyst for transformative processes. To me, this portion of the paper is the least empirically grounded-and the most interesting. Although the authors push well beyond extant data, they theoretically link their hypothetical claims that prayer may serve as a transformative strategy in the well-established work of Gottman and others.

An additional point is that phrases prevalent in Fincham et al. (2007) such as "sudden and discontinuous change," "nonlinear change," "qualitative shifts," and spontaneous recovery (pp. 286, 288) have been reiterated, even extended, in the present piece. Such concepts are, of course, anathema to many developmental scholars who might point out that although Dickens' Ebeneezer Scrooge and Hugo's Jean Valjean made transformative changes, one would be unwise to bet in favor of transformative change at the individual or marital level in the realm of non-fiction. Even given the validity of such a point, I stand with the authors. The social sciences in general and demographers in particular have a strong nomothetic bias: an investment in trends, means, medians, and the like. By contrast, an ideographic perspective might lead us to examine motivational (although rarely realized) possibilities that would offer a different kind of insight. What I am suggesting is that purposively sampling and examining couples who have experienced transformation, qualitative change, spontaneous recovery, or other anomalous improvements would be a valuable starting point. In addition, systematic and empirical testing as mentioned (but underdeveloped) in the paper seems to be the next essential step. Having discussed the three major sections of the paper that deal with the integration of prayer, I now turn to three brief concerns.

\section{SOME CONCERNS}

My first concern is that the subtitle states that the article offers "a conceptual framework." Although the paper offers much, by the au- 
thors' own concluding report "a conceptual framework has not yet been provided." They add that the current manuscript/models should be "viewed as a promissory note." Clearly, there is some work left to do here. Further, the authors' explanations of how certain objectives in the models might be reached through an alternative route of prayer are insightful-but I was left wondering whether these explanations were solely conceptual and theoretical, or whether they were grounded in and drawn from their intervention-based experience and practice.

My second concern is a correlate of the issue that I addressed at the outset of my comments. Namely, if a clinician's failure to mention prayer will be a turn-off for many, the discussion of prayer will likely arouse a similarly strong aversion for others, particularly in regions with a largely non-religious client base. I would like to hear more about the authors' recommendations regarding the delicate dance that extends a warm and inclusive invitation without stepping on the toes of others. As one who has lived and worked in both highly religious communities and predominantly non-religious communities, I can sympathize with the divergent plights of clinicians in both settings.

I will set up my third concern with a two sentence vignette. The story is told of a church-going farmer who was complimented by a fellow congregant, "That is a fine garden you and the Lord have there, brother." To this, the old farmer replied, "Yes, but you should have seen what it looked like when the Lord was doing the gardening alone." On a related note, the authors emphasize their vision that couples must "be empowered to do the constructive things they intend to do" and that they must develop a "sense of efficacy." These are productive aims, but certain forms of prayer that abdicate personal action may lead away from these objectives and toward a type of passive fatalism that seems incongruent with marital intervention and training. My related fear is that there are prayer-prone couples that may expect their God to do their marital gardening and weeding for them. For example, praying "God, if you want my marriage to work, help my spouse to not be such an aggravating jerk" is far less active and facilitative than "God, please soften our hearts and help us to be more patient and understanding with each other." What are the authors' recommendations for promoting the latter? 


\section{SOME HIGHLIGHTS}

I now turn my attention to a few of the highlights of the paper, as I perceived them. Nietzsche stated, "He who has a why to live for can bear with almost any how." Sound marital interventions provide participants with both information and skills designed to help them preserve and enhance relationships. Phrased differently, these interventions typically show participants how to strengthen their marriages. However, few marital interventions address why a marriage is worth the required work. To paraphrase Nietzsche, "A couple who has a sacred motivation for why they want their marriage to survive and flourish will likely be invested in learning how." Indeed, the work of Mahoney and colleagues (2003) has indicated that married couples who view their marriages as sacred or "sanctified" are significantly less likely to divorce. Clinicians are not in the business of answering existential questions regarding the meaning of marriage for the couples in their programs. However, not even asking the difficult "why" question seems counterproductive. The integration of prayer where appropriate, as recommended by Beach and colleagues, seems to implicitly invite couples to revisit and respond to marital existential questions in ways that may be personally and maritally beneficial.

Beach et al.'s piece is likely to arouse considerable controversy. On this note, I mention my second highlight. As the authors note at least twice, the value of integrating prayer as a marital intervention is testable both at clinical and empirical levels. After some additional work in the areas of instrumentation and evaluation, the authors should be able to present data that indicate whether prayer has a negative, non-existent, or additive effect on their program. I am willing to withhold judgment until that time but again note that dramatic regional variation in religiosity prevents generalizability.

A final issue that caught my attention was a small but qualitative shift from the preceding Fincham et al. (2007) article involving the definition of the central construct of transformation. As I mentioned earlier, in the 2007 piece transformation was defined as "sudden and discontinuous" and "nonlinear" (pp. 286, 288). In the present piece, the authors spend the last two or three paragraphs of the section entitled "Prayer as a Transformative Strategy" illustrating how transformation may, in many instances, be "cumulative" or "compound." 
This explanation of how small, positive movements may transform the marriage across time will be more palatable to many readers than the 2007, non-linear definition of marital transformation.

With this said, let us take a momentary detour. The Second Law of Thermodynamics states, "All physical or chemical changes tend to proceed in such a direction that useful energy undergoes irreversible degradation into a randomized form called entropy" (Lehninger, 1982, p. 362). If we prefer the language of the poet over that of the basic sciences, we can turn to Yeats: "Things fall apart; the centre cannot hold; mere anarchy is loosed upon the world." If the principles of entropy and the trend toward disorganization and loss apply to marital relationships at some level-and if leading marriage and family therapist Bill Doherty (2001) is correct in asserting that one of the greatest dangers to marriage is the steady current of daily living that pulls us downstream toward dis-integration-then Beach and colleagues are onto an issue of critical importance with "cumulative" transformation. Viewed in this light, marital transformation is not solely expressed as a one-time, anomalous phenomenon that happens to a few couples on the edge of the bell curve; it may also be a process that perennially produces revitalizing marital energy in many lasting marriages.

In 2007, the authors argued that marriage researchers and professionals should be invested in asking how and why marriages transform. In this piece, they have pushed further to suggest that one critical factor in marital transformation may be prayer. I, for one, will be interested to see if subsequent data support or refute the authors' clinical faith in prayer.

\section{REFERENCES}

Doherty, W. J. (2001). Take back your marriage. Guilford Press: New York.

Fincham, F. D., Stanley, S., \& Beach, S. R. H. (2007). Transformative processes in marriage: An analysis of emerging trends. Journal of Marriage and the Family, 69, 275-292.

Kroll, B., \& Taylor, A. (2003). Parental substance misuse and child welfare. London: Jessica Kingsley Publishers.

Lehninger, A. L. (1982). Principles of biochemistry. New York: Worth.

Mahoney, A., Pargament, K. I., Murray-Swank, A., \& Murray-Swank, N. (2003). 
Religion and the sanctification of family relationships. Review of Religious Research, 44, 220-236.

Mahoney, A., Pargament, K. I., Tarakeshwar, N., \& Swank, A. B. (2001). Religion in the home in the 1980s and 1990s: A meta-analytic review and conceptual analysis of links between religion, marriage, and parenting. Journal of Family Psychology, 15, 559-596.

McCullough, M. E., Hoyt, W. T., Larson, D. B., Koenig, H. G., \& Thoresen, C. E. (2000). Religious involvement and mortality: A meta-analytic review. Health Psychology, 19, 211-222.

Plante, T. G. (1999). A collaborative relationship between professional psychology and the Roman Catholic church. Professional Psychology: Research and Practice, 30, 541-546.

Stark, R., \& Finke, R. (2000). Acts of faith: Explaining the human side of religion. Berkeley, CA: University of California Press. 